Diclofenac Does Not Reduce the Risk of Post-endoscopic Retrograde Cholangiopancreatography Pancreatitis in Low-Risk Units

Rainio, Mia

2017-08

Rainio , M , Lindström , O , Udd , M , Louhimo , J \& Kylänpää , L 2017 , ' Diclofenac Does Not Reduce the Risk of Post-endoscopic Retrograde Cholangiopancreatography Pancreatitis in Low-Risk Units ' , Journal of Gastrointestinal Surgery , vol. 21 , no. 8 , pp. 1270-1277 . https://doi.org/10.1007/s11

http://hdl.handle.net/10138/238725

https://doi.org/10.1007/s11605-017-3412-3

publishedVersion

Downloaded from Helda, University of Helsinki institutional repository.

This is an electronic reprint of the original article.

This reprint may differ from the original in pagination and typographic detail.

Please cite the original version. 


\title{
Diclofenac Does Not Reduce the Risk of Post-endoscopic Retrograde Cholangiopancreatography Pancreatitis in Low-Risk Units
}

\author{
Mia Rainio $^{1}$ (D) $\cdot$ Outi Lindström $^{1} \cdot$ Marianne Udd $^{1} \cdot$ Johanna Louhimo $^{1} \cdot$ \\ Leena Kylänpää ${ }^{1}$
}

Received: 9 January 2017 / Accepted: 26 March 2017 / Published online: 3 April 2017

(C) 2017 The Society for Surgery of the Alimentary Tract

\begin{abstract}
Background Nonsteroidal anti-inflammatory drugs have an inhibitory role in pathogenesis of pancreatitis. Guidelines from the European Society of Gastrointestinal Endoscopy recommend routine rectal administration of $100 \mathrm{mg}$ of diclofenac or indomethacin immediately before or after ERCP for all patients without contraindications.

Aims Our aim was to evaluate the effect of diclofenac in preventing post-ERCP pancreatitis (PEP) in a high-volume, low-PEPrisk ERCP unit.

Methods The rate and severity of PEP were compared in groups of 1000 historical controls prior to the routine use of diclofenac and in 1000 patients receiving $100 \mathrm{mg}$ diclofenac before ERCP.

Results PEP occurred in $56(2.8 \%)$ of the 2000 patients, and the rate of the pancreatitis was $2.8 \%$ in control group and $2.8 \%$ in diclofenac group $(p=1.000)$. The PEP rate among the native papilla patients was $3.9 \%$ in control group and $3.6 \%$ in diclofenac group $(p=0.803)$. In subgroup analysis of patients with a high risk of PEP, diclofenac neither prevented PEP nor made its course milder.

Conclusions In an unselected patient population in a center with a low incidence of PEP, diclofenac seems to have no beneficial effect.
\end{abstract}

Keywords Acute pancreatitis $\cdot$ Diclofenac $\cdot$ ERCP $\cdot$ ESGE recommendation $\cdot$ Post-ERCP pancreatitis

\section{Introduction}

Acute pancreatitis is the most frequent and feared complication of endoscopic retrograde cholangio-pancreatography (ERCP). The occurrence of post-ERCP pancreatitis (PEP) varies between 1 and $25 \%$ depending on risk factors and the indication of ERCP. ${ }^{1-4}$ The vast majority of PEP has a mild or moderate course, but in $0.3-0.6 \%$ of cases, PEP is severe in

Mia Rainio

mia.rainio@hus.fi

1 Department of Gastrointestinal Surgery, University of Helsinki, Helsinki University Hospital, Haartmaninkatu 4, 00290 Helsinki, Finland nature with a need for intensive care and invasive interventions, and at worst, it can even lead to death. ${ }^{2,5,6}$ The pathogenesis of PEP is not clearly understood. Phospholipase A is believed to play a key role in the inflammatory cascade leading to pancreatitis. Nonsteroidal anti-inflammatory drugs (NSAIDs) are potent inhibitors of phospholipase A2 activity, and neutrophil and endothelial cell attachment. With this mechanism, they are believed to play an inhibitory role in the pathogenesis of pancreatitis. ${ }^{7,8}$ The guidelines from the European Society of Gastrointestinal Endoscopy (ESGE) ${ }^{9}$ recommend routine rectal administration of $100 \mathrm{mg}$ of diclofenac or indomethacin for all patients without contraindications immediately before or after ERCP. This guideline is based on eight meta-analyses that all show the benefit of NSAIDs in preventing PEP. ${ }^{10-17}$ The studies in these metaanalyses have strict inclusion and exclusion criteria, and they have mainly been conducted on high-risk patients and procedures. The overall risk of PEP in these studies has been rather high $(6.9-26 \%)$ due to their patient selection. ${ }^{18-26}$ The American Society for Gastrointestinal endoscopy (ASGE) 
recommends rectal indomethacine for the prevention of PEP in average-risk individuals. ${ }^{27}$ In Asia, Japanese guidelines recommend administration of intrarectal NSAIDS for all cases undergoing ERCP with no contraindications. ${ }^{28}$

Commonly known NSAID-related adverse events are gastrointestinal bleeding, ulcer, and perforation as well as adverse events in renal function. However, single dose of NSAIDS in preventing PEP has been safe in earlier studies. ${ }^{19,}{ }^{20}$ On the basis of the ESGE guidelines and earlier research data, we initiated rectal administration of diclofenac to all eligible patients without contraindications referred for ERCP at Helsinki University Hospital (HUH) after November 2013.

The aim of this study was to evaluate the effect of diclofenac in preventing PEP in a high-volume, low-PEPrisk ERCP unit. The annual volume in our unit is 1200 ERCP procedures, and the overall risk of PEP has varied between 2.0 and $3.3 \% .^{29,30}$

\section{Materials and Methods}

In this study, we retrospectively compared 1000 patients who had been rectally administered $100 \mathrm{mg}$ diclofenac before undergoing ERCP (diclofenac group (DG)) to 1000 patients who had not received administration of diclofenac (control group $(\mathrm{CG})$ ). Both groups included all the adult patients $(\geq 18$ years) procedures who were referred to our unit, regardless of the indications for ERCP. The exclusion criteria for DG were contraindications for NSAIDs (renal insufficiency or NSAID allergy). To collect the data for this study, all patient records about ERCP patients were reviewed, and information about age, sex, weight, height, and history of acute pancreatitis, chronic pancreatitis, or PEP were recorded. The results of laboratory tests, including plasma bilirubin and amylase levels before ERCP, were collected, as well as plasma amylase levels $4 \mathrm{~h}$ after ERCP and, if the patient stayed overnight, $24 \mathrm{~h}$ after ERCP. All the ERCP-related details were explored: indication, type and difficulty of procedure, type of cannulation, duration of cannulation of native papillae, pancreatic duct opacification, and duration of ERCP. The difficulty of the procedure was scored using the scale presented by Cotton et al. ${ }^{31}$ Biliary cannulation of native papilla was defined as "difficult" if there were more than five attempts, the guide wire passed into the pancreatic duct two times or the primary cannulation was unsuccessful after $5 \mathrm{~min}$. Data about biliary duct cannulation time was available only for 506 patients of the 934 native papilla patients whose bile duct cannulation was attempted. Therefore, we also interpreted the cannulation as difficult if there was a need for a second cannulation method to get access to the bile duct. The time of hospitalization was recorded, and the patient history was followed 30 days after ERCP to explore possible readmissions due to ERCPrelated adverse events or late onset of PEP.
PEP was diagnosed if there was an elevation in amylase exceeding three times the upper limit of normal four or $24 \mathrm{~h}$ after the procedure with pancreas-specific abdominal pain requiring hospitalization or prolonging initial discharge from hospital by more than 1 day. ${ }^{32}$ The severity of PEP was classified according to the revised Atlanta consensus criteria. ${ }^{33}$ Other adverse events, such as perforation and bleeding, were classified according to the Cotton consensus criteria. ${ }^{32,} 33$ Perforation was defined if there was a visible leak of contrast dye or a suspicion of guide wire perforation during the ERCP, or if air and fluids were visible in a computed tomography (CT) scan after ERCP.

All ERCP procedures were performed or supervised by four experienced interventional operators who each undertake around 300 ERCPs a year. Their individual rate of PEP varied between 2.7 and $3.6 \%$ in this study.

The primary outcome of this study was to assess the incidence of PEP in the CG and DG, as well as in known higherrisk subgroups, such as patients with native papillae, pancreatic sphincterotomies, papillectomies, pancreatic brush cytology, normal bilirubin level, difficult biliary cannulation, and female patients. The secondary outcome was to resolve weather the administration of diclofenac makes the course of PEP milder.

In previous analyses, the risk of PEP in our unit has been $2.0-3.3 \% .^{29,30}$ The sample size determination for this study was carried out as follows: power $=0.8 ; \alpha=0.05$; and to lower the risk from 3.0 to $1.0 \%$ needs a sample of 1528 patients $(764+764)$. We included 2000 patients in this study. The analysis was performed using SPSS version 22.0 (IBM Corporation, Somers, NY) statistical software. Differences in demographic variables between the CG and the DG were analyzed using the chi-square test or Fisher's exact test for categorical variables and the nonparametric Wilcoxon-MannWhitney test for continuous variables. The same tests were used to further analyze the associations between variables and PEP. To show the effect of diclofenac in groups with risk factors for PEP, each individual risk subgroup was separately adjusted for diclofenac administration in a logistic regression analysis. In addition, all variables that had $p<0.05$ in the univariate analysis were selected for multivariate logistic regression analysis in order to identify potential confounding variables for PEP. The results were presented as odds ratios (ORs) with 95\% confidence intervals (95\% CIs). Probabilities below 0.05 were regarded as statistically significant.

\section{Results}

Most of the ERCPs were therapeutic procedures (97\%). The most common procedure was a biliary sphincterotomy, and it was performed 1327 times. After the sphincterotomy, the most common procedures were biliary stent placement or removal 
(749) and biliary stone removal (459). Half of the patients (1058) had native papillae, and the median cannulation time of native papilla was $92 \mathrm{~s}$. The median total time of the procedure was $21 \mathrm{~min}$ in all patients, as it was $21 \mathrm{~min}$ in native papilla cases as well. According to the criteria used, the biliary cannulation of native papilla was rated as difficult in 328 cases $(31 \%)$.
The baseline characteristics of the study groups (CG and DG) are shown in Table 1. The possible patient-related risk factors for PEP were similar in these two groups with four exceptions. (1) Sixteen patients in the CG and only 6 patients in the DG had a history of earlier PEP $(p=0.032)$. This patient group was very small, and therefore, the result has no clinical relevance. (2) More pancreatic sphincterotomies were
Table 1 Patient and procedure characteristics

\begin{tabular}{|c|c|c|c|}
\hline Characteristic & $\begin{array}{l}\text { Control group } \\
(n=1000)\end{array}$ & $\begin{array}{l}\text { Diclofenac group } \\
(n=1000)\end{array}$ & $p$ \\
\hline $\operatorname{Age}^{\mathrm{a}}$ (years) & $63(18-100)$ & $64(18-97)$ & 0.358 \\
\hline Female, $n(\%)$ & $421(42.1)$ & $430(43)$ & 0.684 \\
\hline ASA grade, $n(\%)$ & & & 0.697 \\
\hline 1 & $31(3.1)$ & $39(3.9)$ & \\
\hline 2 & $244(24.4)$ & $215(21.5)$ & \\
\hline 3 & $536(53.6)$ & $589(58.9)$ & \\
\hline 4 & $189(18.9)$ & $157(15.7)$ & \\
\hline $\mathrm{BMI}^{\mathrm{a}}\left(\mathrm{kg} / \mathrm{m}^{2}\right)$ & $24.8(12.8-56.2)$ & $24.8(12.4-56)$ & 0.897 \\
\hline Normal serum bilirubin, $n(\%)$ & $521(52)$ & $505(51)$ & 0.315 \\
\hline Native papilla, $n(\%)$ & $535(53.5)$ & $523(52.3)$ & 0.624 \\
\hline History of acute pancreatitis, $n(\%)$ & $137(13.7)$ & $142(14.2)$ & 0.747 \\
\hline History of post-ERCP pancreatitis, $n(\%)$ & $16(16)$ & $6(6.0)$ & 0.032 \\
\hline ERCP grade $^{\mathrm{b}}, n(\%)$ & & & 0.814 \\
\hline 1 & $61(6.1)$ & $79(7.9)$ & \\
\hline 2 & $546(54.6)$ & $495(49.5)$ & \\
\hline 3 & $274(27.4)$ & $334(33.4)$ & \\
\hline 4 & $119(11.9)$ & $92(9.2)$ & \\
\hline \multicolumn{4}{|l|}{ Indication, $n(\%)$} \\
\hline Biliary stone & $286(28.6)$ & $293(29.3)$ & 0.762 \\
\hline Biliary stricture & $399(39.9)$ & $412(41.2)$ & 0.566 \\
\hline PSC & $4(0.4)$ & $8(0.8)$ & 0.247 \\
\hline Bile duct injury after cholecystectomy & $38(3.8)$ & $20(2.0)$ & 0.016 \\
\hline Problems after liver transplantation & $36(3.6)$ & $14(1.4)$ & 0.002 \\
\hline Chronic pancreatitis & $216(21.6)$ & $209(20.9)$ & 0.702 \\
\hline Pancreatic pseudocyst & $99(9.9)$ & $84(8.4)$ & 0.239 \\
\hline Papillectomy & $12(1.2)$ & $12(1.2)$ & 1.000 \\
\hline \multicolumn{4}{|l|}{ Therapy, $n(\%)$} \\
\hline Biliary stent & $368(36.8)$ & $381(38.1)$ & 0.483 \\
\hline Biliary sphincterotomy & $500(50.0)$ & $468(46.8)$ & 0.133 \\
\hline Biliary stone removal & $218(21.8)$ & $240(24.0)$ & 0.124 \\
\hline Precut & $15(1.5)$ & $18(1.8)$ & 0.593 \\
\hline Pancreatic sphincterotomy & $192(19.2)$ & $158(15.8)$ & 0.045 \\
\hline Pancreatic stent & $239(23.9)$ & $258(25.8)$ & 0.313 \\
\hline Pancreatic brush cytology & $32(3.2)$ & $41(4.1)$ & 0.340 \\
\hline Pseudocyst transmural drainage & $18(1.8)$ & $17(1.7)$ & 0.860 \\
\hline Papillectomy & $12(1.2)$ & $12(1.2)$ & 1.000 \\
\hline $\begin{array}{l}\text { Difficult biliary cannulation, native papilla, } n \\
\qquad(\%)\end{array}$ & $168(31.4)$ & $160(30.6)$ & 0.629 \\
\hline Pancreatic duct opacification, $n(\%)$ & $332(33.2)$ & $347(34.7)$ & 0.479 \\
\hline Duration of procedure $(\mathrm{min})^{\mathrm{a}}$ & $21(3-153)$ & $21(2-148)$ & 0.005 \\
\hline Duration of cannulation, native papilla $(\mathrm{s})^{\mathrm{a}}$ & $105(0-3720)$ & $91(0-3030)$ & 0.421 \\
\hline Length of hospital stay after ERCP ${ }^{\mathrm{a}}$ & $1(0-106)$ & $1(0-87)$ & 0.015 \\
\hline Operator, $n(\%)$ & & & 0.000 \\
\hline $1 \mathrm{JH}$ & $332(33.2)$ & $200(20.0)$ & \\
\hline $2 \mathrm{LK}$ & $252(25.2)$ & $211(21.1)$ & \\
\hline $3 \mathrm{OL}$ & $168(16.8)$ & $211(21.1)$ & \\
\hline $4 \mathrm{MU}$ & $195(19.5)$ & $173(17.3)$ & \\
\hline 5 Trainee involvement in ERCP & $53(5.3)$ & $205(20.5)$ & \\
\hline
\end{tabular}

$A S A$ American Society of Anesthesiology, BMI body mass index, ERCP endoscopic retrograde cholangiopancreatography, $P S C$ primary sclerosing cholangitis

${ }^{\text {a }}$ Data are presented as numbers and (\%) percentages of patients or as median (range)

${ }^{\mathrm{b}}$ ERCP grade according to Cotton classification 
performed in the CG (192 patients) than in the DG (158 patients, $p=0.045$ ). (3) The median duration of the procedure was $21 \mathrm{~min}$ in both groups; however, in the CG, 117 operations took longer than 45 min compared to the DG with 143 operations lasting more than $45 \mathrm{~min}$, and in the DG, the total time of procedure was longer $(p=0.002)$. (4) Patients in the CG stayed longer in hospital after ERCP than patients in the DG $(p=0.015)$. The median time in both groups was 1 day, but patients in DG were discharged more often on the day of operation. The reason for this difference is the change of our policy after having a new big daycare unit in our hospital, which made it possible to discharge patients on the day of procedure. However, there was no difference between the groups in the number of inpatients after day $1(p=0.396)$.

The incidence of PEP in the different risk groups is shown in Table 2. PEP occurred in $56(2.8 \%)$ of the 2000 patients, and its distribution was equal in both groups: $2.8 \%$ in the CG and $2.8 \%$ in the DG $(p=1.000)$. The PEP rate among the native papilla patients was $3.9 \%$ in the CG and $3.6 \%$ in the DG $(p=0.803)$. There were no significant differences between the CG and DG groups in the distribution of any PEP risk group (Table 2).

In univariate analyses, the risk factors for PEP were found to be native papilla, pancreatic sphincterotomy, pancreatic brush cytology, papillectomy, precut sphincterotomy, difficult cannulation, and prolonged time of procedure (Table 3). We chose these variables for pair-wise logistic regression analysis together with the administration of diclofenac, which did not have an effect on the risk of PEP in these analyses (data not shown). We also carried out a multivariate analysis on these risk factors and the administration of diclofenac. In multivariate analysis, four factors were significantly associated with the risk of PEP: pancreatic sphincterotomy, pancreatic brush cytology, difficult cannulation, and prolonged time of procedure. Administration of diclofenac did not show any effect on the risk of PEP (Table 4).

In the whole cohort, 35 patients (1.8\%) had mild PEP, 18 patients $(0.9 \%)$ had moderately severe PEP, and three patients $(0.15 \%)$ had severe PEP according to the revised Atlanta criteria. There was no difference between the groups in the severity of PEP $(p=0.877)$ (Table 5).

Adverse events of ERCP other than PEP are shown in Table 6. Significant bleeding after ERCP occurred in 15 patients $(0.75 \%)$ : ten incidents of bleeding in the $C G$ and five incidents in the DG. The bleeding was classified as severe in ten patients. Most of the severe bleeding cases were mild to moderate in nature, but because we promptly performed endoscopy and electrocoagulation of the bleeding site after blood clot removal, they were categorized as a more severe event. There was no association between bleeding and administration of diclofenac. There were 21 incidents of perforation (1\%) after ERCP. Seven were graded as a mild perforation, seven as moderate, and seven as severe. The reason for the perforation was guide wire perforation in nine patients, sphincterotomy in six patients, papillectomy in two patients, biliary dilatation with biliary stones in two patients, duodenal
Table 2 Incidence of postendoscopic retrograde cholangiopancreatography pancreatitis according to risk factors

\begin{tabular}{llll}
\hline Risk factors $n / N(\%)$ & CG & DG & $p$ \\
\hline Native papilla & $21 / 535(3.9)$ & $19 / 523(3.6)$ & 0.803 \\
Female sex & $13 / 408(3.2)$ & $14 / 416(3.4)$ & 0.889 \\
Native papilla, female & $12 / 241(4.9)$ & $13 / 249(5.2)$ & 0.900 \\
Native papilla, female under 40 years & $1 / 24(4.2)$ & $0 / 28(0)$ & $0.462^{\mathrm{a}}$ \\
History of pancreatitis & $2 / 137(1.5)$ & $2 / 142(1.4)$ & $1.000^{\mathrm{a}}$ \\
History of PEP & $1 / 16(6.3)$ & $0 / 6(0)$ & $1.000^{\mathrm{a}}$ \\
Difficult biliary cannulation, native papilla & $12 / 156(7.7)$ & $10 / 150(6.7)$ & 0.747 \\
Duration of ERCP $>40$ min & $12 / 145(8.2)$ & $9 / 169(5.3)$ & 0.3300 \\
Normal serum bilirubin & $14 / 457(3.1)$ & $10 / 485(2.1)$ & 0.330 \\
Pancreatic sphincterotomy & $17 / 192(8.9)$ & $12 / 158(7.6)$ & 0.671 \\
Biliary sphincterotomy & $21 / 500(4.2)$ & $13 / 468(2.8)$ & 0.230 \\
Pancreatic duct dilatation & $5 / 108(4.6)$ & $4 / 120(3.3)$ & $0.739^{\mathrm{a}}$ \\
Pancreatic stent placement & $6 / 239(2.5)$ & $10 / 258(3.9)$ & 0.389 \\
Pancreatic cytology & $8 / 153(5.2)$ & $6 / 194(3.1)$ & 0.335 \\
Pancreatic duct opacification & $10 / 322(3.1)$ & $14 / 333(4.2)$ & 0.471 \\
Precut & $1 / 15(6.7)$ & $2 / 18(11.1)$ & $1.000^{\mathrm{a}}$ \\
Papillectomy & $1 / 12(8.3)$ & $3 / 12(25)$ & $0.590^{\mathrm{a}}$ \\
\hline
\end{tabular}

Data are presented as numbers

$n$ number of pancreatitis cases, $N$ group size, $\%$ percentages

${ }^{a}$ Fisher's exact test 
Table 3 Factors associated with postendoscopic retrograde cholangiopancreatography pancreatitis, univariate analysis

\begin{tabular}{|c|c|c|}
\hline & OR $(95 \% \mathrm{CI})$ & $p$ \\
\hline Age & $0.99(0.97-1.008)$ & 0.216 \\
\hline Sex & & 0.385 \\
\hline Female & 1.11 & \\
\hline Male & $0.88(0.67-1.16)$ & \\
\hline BMI $\left(\mathrm{kg} / \mathrm{m}^{2}\right)$ & $0.999(0.95-1.050)$ & 0.971 \\
\hline Administration of diclofenac & & 1.000 \\
\hline No & 1.000 & \\
\hline Yes & $1.000(0.77-1.30)$ & \\
\hline Native papilla & & 0.005 \\
\hline No & 0.73 & \\
\hline Yes & $1.67(1.10-2.52)$ & \\
\hline History of acute pancreatitis & & 0.136 \\
\hline No & 0.93 & \\
\hline Yes & $1.98(0.77-5.12)$ & \\
\hline History of PEP & & 0.618 \\
\hline No & 0.605 & \\
\hline Yes & $1.01(0.97-1.04)$ & \\
\hline Chronic pancreatitis & & 0.529 \\
\hline No & 1.20 & \\
\hline Yes & $0.96(0.84-1.08)$ & \\
\hline Difficult biliary cannulation of native papilla & & 0.000 \\
\hline No & 0.40 & \\
\hline Yes & $1.39(1.12-1.71)$ & \\
\hline Biliary stone & & 0.484 \\
\hline No & 0.85 & \\
\hline Yes & $1.05(0.90-1.24)$ & \\
\hline Normal bilirubin & & 0.50 \\
\hline No & 0.91 & \\
\hline Yes & $1.12(0.83-1.52)$ & \\
\hline Papillectomy & & 0.004 \\
\hline No & 0.144 & \\
\hline Yes & $1.066(0.99-1.15)$ & \\
\hline Biliary sphincterotomy & & 0.067 \\
\hline No & 0.80 & \\
\hline Yes & $1.32(0.95-1.83)$ & \\
\hline Pancreatic sphincterotomy & & 0.000 \\
\hline No & 0.319 & \\
\hline Yes & $1.73(1.32-2.27)$ & \\
\hline Pancreatic brush cytology & & 0.04 \\
\hline No & 0.32 & \\
\hline Yes & $1.08(0.98-1.18)$ & \\
\hline Precut & & 0.027 \\
\hline No & 0.288 & \\
\hline Yes & $1.040(0.98-1.11)$ & \\
\hline Pancreatic duct opacification & & 0.153 \\
\hline No & 0.786 & \\
\hline Yes & $1.160(0.92-1.46)$ & \\
\hline Duration of cannulation & $1.000(1.000-1.000)$ & 0.172 \\
\hline \multicolumn{3}{|l|}{ Perforation } \\
\hline No & 0.115 & \\
\hline Yes & $1.068(0.99-1.14)$ & 0.000 \\
\hline Duration of procedure & $1.025(1.01-1.04)$ & 0.000 \\
\hline Operator & $1.012(0.82-1.24)$ & 0.907 \\
\hline
\end{tabular}

$B M I$ body mass index

dilatation in one patient, and pharyngeal perforation in one patient. Surgery was needed for only one patient with duodenal perforation; the others recovered after drainage and antibiotics, and in the cases of guide wire perforation, even without any treatment. The incidents of perforation were equally
Table 4 Logistic regression analysis on the effect of diclofenac on the risk of PEP when adjusting for the risk of PEP in a univariate analysis

\begin{tabular}{lll}
\hline & OR $(95 \% \mathrm{CI})$ & $P$ \\
\hline Administration of diclofenac & $1.031(0.60-1.79)$ & 0.913 \\
Native papilla & $1.099(0.53-2.28)$ & 0.800 \\
Pancreatic sphincterotomy & $2.857(1.49-5.47)$ & 0.002 \\
Pancreatic cytology & $3.189(1.233-8.250)$ & 0.017 \\
Precut & $1.125(0.29-4.39)$ & 0.865 \\
Difficult biliary cannulation & $2.145(1.10-4.20)$ & 0.026 \\
Papillectomy & $2.818(0.788-10.08)$ & 0.111 \\
Duration of procedure & $1.020(1.01-1.03)$ & 0.001 \\
\hline
\end{tabular}

distributed between the CG and DG (11 and ten, $p=0.513$ ). Post-ERCP cholangitis was diagnosed in 15 patients $(0.75 \%)$, nine in the CG, and six in the DG $(p=0.71)$.

Prophylactic pancreatic stents were placed only 22 times to prevent PEP. There were 11 stents in both groups. Indications for prophylactic pancreatic stent were papillectomy in 11 patients and difficult cannulation in 11 patients (five biliary stone removals, five biliary tumor strictures, and one biliary stricture after liver transplantation). One patient with a prophylactic stent had mild PEP.

The 30 -day mortality was $3.1 \%$ ( 55 patients). The median age of this group was 74 years (range 55-93). The most common cause of death was widely spread malignancy (44 patients). Other coexisting diseases, such as pneumonia or sepsis, were the cause of death in nine patients. Two patients $(0.1 \%)$ died due to complications from the ERCP; one patient in the CG had a perforation due to a sphincterotomy and biliary stone removal, and another had severe PEP (ages 93 and 87 years, respectively).

\section{Discussion}

The aim of our study was to determine the efficacy of prophylactic rectal diclofenac in preventing PEP and reducing the severity of its clinical course. We assessed the effects of diclofenac on our unselected patient population. Statistical analyses showed no difference in the risk or the severity of PEP between the CG and DG in pair-wise logistic regression analysis with known risk factors for PEP. In a multivariate logistic regression analysis including patient- and processrelated risk factors, diclofenac did not have an effect in the risk of PEP. The overall incidence of PEP in this study was $2.8 \%$. According to our routine protocol, we measure plasma amylase $4 \mathrm{~h}$ after the procedure from all ERCP patients. This protocol may even increase the rate of PEP in our unit, even though abdominal pain is needed for the diagnosis of PEP. In centers where amylase is measured only in cases of abdominal pain, mild cases of PEP that resolve spontaneously with 
Table 5 Severity of postendoscopic retrograde cholangiopancreatography pancreatitis (PEP) according to revised Atlanta criteria

\begin{tabular}{lllll}
\hline & All & CG & DG & $p$ \\
\hline PEP, $n(\%)$ & $56(2.8)$ & $28(2.8)$ & $28(2.8)$ & 1.000 \\
Mild & 35 & $18(1.8)$ & $17(1.7)$ & 1.000 \\
Moderately severe & 18 & $8(0.8)$ & $10(1.0)$ & 0.865 \\
Severe & 3 & $2(0.2)$ & $1(0.1)$ & 0.636 \\
PEP in native papilla patients, $n(\%)$ & $40(3.8)$ & $21(4.1)$ & $19(3.8)$ & 0.896 \\
Mild & $23(2.2)$ & $13(2.4)$ & $10(1.9)$ & 0.803 \\
Moderately severe & $14(1.3)$ & $6(1.1)$ & $8(1.5)$ & 0.564 \\
Severe & $3(0.3)$ & $2(0.4)$ & $1(0.2)$ & 0.561 \\
\hline
\end{tabular}

Data are presented as number and $(\%)$ of patients

painkillers may be missed. The risk of severe PEP in our present study is $0.15 \%$ according to the Atlanta criteria. ${ }^{33}$ The low rate of PEP in our present study differs from the other previous studies, which were conducted with a much higher incidence of PEP, showing a clear effect of diclofenac or indomethacin in reducing the risk of PEP. ${ }^{18,19,21,23,25,34}$ Three other recently published randomized trials have similar results to ours, showing no effect of indomethacin or diclofenac in preventing PEP. ${ }^{22,} 35,{ }^{36}$ However, they include a relatively low number of patients $(n=144, n=665$, and $n=449$, respectively). Our cohort differs from these due to its larger volume, with 2000 patients and 1056 native papillae. Our results indicate that the role of NSAIDS in preventing PEP is not clear and further randomized controlled trials are needed to explore its routine use for all patients, especially in centers with low PEP risk.

Absence of chronic pancreatitis, normal serum bilirubin, and a previous episode of acute pancreatitis are known as patient-related risk factors of PEP, and female patients are also known to be at a higher risk. Procedure-related risk factors include difficult cannulation, repeated contrast injection of the pancreatic duct, pancreatic acinar opacification, and precut or needle-knife sphincterotomy. ${ }^{2,4,5,37}$ All kinds of mechanical manipulation of the pancreatic duct can cause obstruction of or prolonged spasms in the pancreatic sphincter. Although our study is retrospective in nature and therefore has some limitations, it involves a large cohort of patients and explores the effects of diclofenac in our patients; our unit has been keeping a thorough register of all ERCP procedures for several years. These known PEP risk factors exist in our present study: 1058 patients had native papilla (3.8\% risk of PEP in our study), 1026 patients had normal serum bilirubin (3.0\% risk of PEP), 279 patients had previous history of pancreatitis (1.4\% risk of PEP), difficult cannulation occurred 326 times (6.7\% risk of PEP), pancreatic sphincterotomy was performed 350 times (8.3\% risk of PEP), and the rate of therapeutic ERCPs was as high as $97 \%$. The patient material was not selected, with the exception of very few sclerosing cholangitis patients, who are mainly treated in the gastroenterological internal medicine endoscopic unit at our hospital, and patients with sphincter of Oddi dysfunction, which seem to be scarce in the Finnish population.

There were some differences between the patient characteristics of the CG and DG. The variation of operators between the groups is due to the trainees in our unit, especially two trainees after November 2013 (DG). All trainees performing ERCPs were supervised and assisted by the same four experienced endoscopists, who carried out most of the ERCPs. All the procedures were performed in the same manner, and there were no changes in the ERCP protocol during the study period. Trainees were involved in the easiest procedures, and their risk of PEP remained low (1.8-2.3\%). Analyzing only the 1742 patients, whose procedure was performed by the four experienced endoscopists, the risk of PEP did not differ between CG and DG, similar to the whole cohort $(p=0.939)$. More pancreatic sphincterotomies were also performed in the CG than in the DG $(p=0.045)$. Pancreatic sphincterotomy is a risk factor for
Table 6 Other endoscopic retrograde

cholangiopancreatographyrelated adverse events according to Cotton classification

\begin{tabular}{lllll}
\hline & All & CG & DG & $p$ \\
\hline Bleeding, n (\%) & $15(0.75)$ & $10(1.0)$ & $5(0.5)$ & 0.120 \\
Mild & 4 & 2 & 2 & \\
Moderate & 1 & 0 & 1 & \\
Severe & 10 & 8 & 2 & 0.513 \\
Perforation, n (\%) & $21(1)$ & $12(1.2)$ & $9(0.9)$ & \\
Mild & 7 & 4 & 3 & \\
Moderate & 7 & 4 & 3 & 0.446 \\
Severe & 7 & 4 & $6(0.6)$ & \\
Cholangitis, n (\%) & $15(0.75)$ & $9(0.9)$ & 1 & \\
Mild & 3 & 2 & 5 & \\
Moderate & 12 & 7 & 0 & \\
Severe & 0 & 0 & & \\
\hline
\end{tabular}

Data are presented as numbers and $(\%)$ percentages of patients 
PEP, and therefore, it can distort the results. However, since in this study, more pancreatic sphincterotomies were performed in the $\mathrm{CG}$, it does not interfere with the effects of the diclofenac. The difference between the durations of the procedures between the groups can be explained partly by the initiation of routine double-balloon ERCPs and cholangioscopies, which our unit adopted in 2012. They are longer procedures, with mean operating times of 59 and $72 \mathrm{~min}$. There were only one double-balloon ERCP and three cholangioscopy ERCPs in the CG, whereas these numbers were 19 and 30 in the DG. Their risk profile for PEP did not differ from the other procedures in this study.

\section{Conclusion}

In an unselected patient population in a center with a low incidence of PEP, diclofenac seems to have no beneficial effect on the risk of PEP.

Authors' Contributions MR collected clinical data, performed a part of the data analysis, and drafted the manuscript. OL and LK participated in designing and coordinating the study, collected clinical data, and provided supervision. MU collected clinical data and provided supervision. JL performed statistical analysis. All authors critically revised the manuscript and read and approved the final version.

\section{Compliance with Ethical Standards}

Conflict of Interest The authors declare that they have no conflict of interest.

Funding This study was supported by the Helsinki University Hospital Research Funds, Helsinki, Finland.

\section{References}

1. Andriulli A, Loperfido S, Napolitano G, et al. Incidence rates of post-ERCP complications: A systematic survey of prospective studies. Am J Gastroenterol. 2007;102:1781-1788.

2. Freeman ML, DiSario JA, Nelson DB, et al. Risk factors for postERCP pancreatitis: A prospective, multicenter study. Gastrointest Endosc. 2001;54:425-434.

3. Rabenstein T, Hahn EG. Post-ERCP pancreatitis: New momentum. Endoscopy. 2002;34:325-329. doi:10.1055/s-2002-23651.

4. Vandervoort J, Soetikno RM, Tham TC, et al. Risk factors for complications after performance of ERCP. Gastrointest Endosc. 2002;56:652-656. doi:10.1067/mge.2002.129086.

5. Freeman ML, Nelson DB, Sherman S, et al. Complications of endoscopic biliary sphincterotomy. N Engl J Med. 1996;335:909918. doi:10.1056/NEJM199609263351301.

6. Masci E, Toti G, Mariani A, et al. Complications of diagnostic and therapeutic ERCP: A prospective multicenter study. Am J Gastroenterol. 2001;96:417-423.

7. Makela A, Kuusi T, Schroder T. Inhibition of serum phospholipase-A2 in acute pancreatitis by pharmacological agents in vitro. Scand J Clin Lab Invest. 1997;57:401-407. doi:10.3109/00365519709084587.
8. Davies NM, Anderson KE. Clinical pharmacokinetics of diclofenac. therapeutic insights and pitfalls. Clin Pharmacokinet. 1997;33:184-213. doi:10.2165/00003088-199733030-00003.

9. Dumonceau J, Andriulli A, Elmunzer BJ, et al. Prophylaxis of postERCP pancreatitis: European society of gastrointestinal endoscopy (ESGE) guideline - updated june 2014. Endoscopy. 2014;46:799815.

10. Dai HF, Wang XW, Zhao K. Role of nonsteroidal antiinflammatory drugs in the prevention of post-ERCP pancreatitis: A meta-analysis. Hepatobiliary Pancreat Dis Int. 2009;8:11-16.

11. Ding X, Chen M, Huang S, Zhang S, Zou X. Nonsteroidal antiinflammatory drugs for prevention of post-ERCP pancreatitis: A meta-analysis. Gastrointest Endosc. 2012;76:1152-1159. doi:10. 1016/j.gie.2012.08.021.

12. Elmunzer BJ, Waljee AK, Elta GH, Taylor JR, Fehmi SM, Higgins PD. A meta-analysis of rectal NSAIDs in the prevention of postERCP pancreatitis. Gut. 2008;57:1262-1267. doi:10.1136/gut. 2007.140756.

13. Sethi S, Sethi N, Wadhwa V, Garud S, Brown A. A meta-analysis on the role of rectal diclofenac and indomethacin in the prevention of post-endoscopic retrograde cholangiopancreatography pancreatitis. Pancreas. 2014;43:190-197. doi:10.1097/MPA.0000000000000090.

14. Sun H, Han B, Zhai H, Cheng X, Ma K. Rectal NSAIDs for the prevention of post-ERCP pancreatitis: A meta-analysis of randomized controlled trials. The Surgeon. 2014;12:141-147. doi:10.1016/ j.surge.2013.10.010.

15. Yaghoobi M, Rolland S, Waschke KA, et al. Meta-analysis: Rectal indomethacin for the prevention of post-ERCP pancreatitis. Aliment Pharmacol Ther. 2013;38:995-1001. doi:10.1111/apt. 12488.

16. Yuhara H, Ogawa M, Kawaguchi Y, Igarashi M, Shimosegawa T, Mine T. Pharmacologic prophylaxis of post-endoscopic retrograde cholangiopancreatography pancreatitis: Protease inhibitors and NSAIDs in a meta-analysis. J Gastroenterol. 2014;49:388-399. doi:10.1007/s00535-013-0834-x.

17. Zheng MH, Xia HH, Chen YP. Rectal administration of NSAIDs in the prevention of post-ERCP pancreatitis: A complementary metaanalysis. Gut. 2008;57:1632-1633.

18. Elmunzer BJ, Scheiman JM, Lehman GA, et al. A randomized trial of rectal indomethacin to prevent post-ERCP pancreatitis. N Engl J Med. 2012;366:1414-1422. doi:10.1056/NEJMoa1111103.

19. Khoshbaten M, Khorram H, Madad L, Ehsani Ardakani MJ, Farzin $\mathrm{H}$, Zali MR. Role of diclofenac in reducing post-endoscopic retrograde cholangiopancreatography pancreatitis. J Gastroenterol Hepatol. 2008;23:e11-6.

20. Murray B, Carter R, Imrie C, Evans S, O'Suilleabhain C. Diclofenac reduces the incidence of acute pancreatitis after endoscopic retrograde cholangiopancreatography. Gastroenterology. 2003;124:1786-1791.

21. Otsuka T, Kawazoe S, Nakashita S, et al. Low-dose rectal diclofenac for prevention of post-endoscopic retrograde cholangiopancreatography pancreatitis: A randomized controlled trial. J Gastroenterol. 2012;47:912-917. doi:10.1007/s00535-0120554-7.

22. Lua GW, Muthukaruppan R, Menon J. Can rectal diclofenac prevent post endoscopic retrograde cholangiopancreatography pancreatitis?. Digestive Diseases \& Sciences. 2015;60:3118-3123.

23. Sotoudehmanesh R, Khatibian M, Kolahdoozan S, Ainechi S, Malboosbaf R, Nouraie M. Indomethacin may reduce the incidence and severity of acute pancreatitis after ERCP. Am J Gastroenterol. 2007;102:978-983.

24. Cheon YK, Cho KB, Watkins JL, et al. Efficacy of diclofenac in the prevention of post-ERCP pancreatitis in predominantly high-risk patients: A randomized double-blind prospective trial. Gastrointest Endosc. 2007;66:1126-1132. 
25. Murray WR. Reducing the incidence and severity of post ERCP pancreatitis. Scand J Surg. 2005;94:112-116.

26. Sotoudehmanesh R, Eloubeidi MA, Asgari AA, Farsinejad M, Khatibian M. A randomized trial of rectal indomethacin and sublingual nitrates to prevent post-ERCP pancreatitis. Am J Gastroenterol. 2014;109:903-909. doi:10.1038/ajg.2014.9.

27. ASGE Standards of Practice Committee, Chandrasekhara V, Khashab MA, et al. Adverse events associated with ERCP. Gastrointest Endosc. 2017;85:32-47.

28. Isaji S, Takada $\mathrm{T}$, Mayumi $\mathrm{T}$, et al. Revised japanese guidelines for the management of acute pancreatitis 2015: Revised concepts and updated points. J Hepatobiliary Pancreat Sci. 2015;22:433-445. doi:10.1002/jhbp. 260.

29. Halttunen J, Kylanpaa L. A prospective randomized study of thin versus regular-sized guide wire in wire-guided cannulation. Surg Endosc. 2013;27:1662-1667. doi:10.1007/s00464-012-2653-1.

30. Kylanpaa L, Boyd S, Ristimaki A, Lindstrom O, Udd M, Halttunen J. A prospective randomised study of dense infinity cytological brush versus regularly used brush in pancreaticobiliary malignancy. Scand J Gastroenterol. 2016;51:590-593. doi:10.3109/00365521. 2015.1121514.

31. Cotton PB, Eisen G, Romagnuolo J, et al. Grading the complexity of endoscopic procedures: Results of an ASGE working party. Gastrointest Endosc. 2011;73:868-874. doi:10.1016/j.gie.2010.12. 036.
32. Cotton PB, Garrow DA, Gallagher J, Romagnuolo J. Risk factors for complications after ERCP: A multivariate analysis of 11,497 procedures over 12 years. Gastrointest Endosc. 2009;70:80-88. doi:10.1016/j.gie.2008.10.039.

33. Sarr MG, Banks PA, Bollen TL, et al. The new revised classification of acute pancreatitis 2012. Surg Clin North Am. 2013;93:549 562. doi:10.1016/j.suc.2013.02.012.

34. Leerhoy B, Nordholm-Carstensen A, Novovic S, Hansen MB, Jorgensen LN. Diclofenac is associated with a reduced incidence of post-endoscopic retrograde cholangiopancreatography pancreatitis: Results from a danish cohort study. Pancreas. 2014;43:12861290. doi:10.1097/MPA.0000000000000169.

35. Dobronte Z, Szepes Z, Izbeki F, et al. Is rectal indomethacin effective in preventing of post-endoscopic retrograde cholangiopancreatography pancreatitis? World J Gastroenterol. 2014;20:10151-10157. doi:10. 3748/wjg.v20.i29.10151.

36. Levenick JM, Gordon SR, Fadden LL, et al. Rectal indomethacin does not prevent post-ERCP pancreatitis in consecutive patients. Gastroenterology. 2016;150:911-7; quiz e19. doi:10.1053/j. gastro.2015.12.040.

37. Halttunen J, Keranen I, Udd M, Kylanpaa L. Pancreatic sphincterotomy versus needle knife precut in difficult biliary cannulation. Surg Endosc. 2009;23:745-749. doi:10.1007/s00464008-0056-0. 